\title{
DISCRETE MODEL OF PAIRED RELAY-RACE
}

\author{
E.V. Larkin ${ }^{1}$, A.V. Bogomolov ${ }^{2}$, A.N. Privalov ${ }^{3}$, N.N. Dobrovolsky ${ }^{1}$ \\ ${ }^{1}$ Tula State University, Tula, Russian Federation \\ ${ }^{2}$ Burnasyan Federal Medical Biophysical Center of Federal Medical Biological Agency, \\ Moscow, Russian Federation \\ ${ }^{3}$ Tula State Lev Tolstoy Pedagogical University, Tula, Russian Federation \\ E-mail: elarkin@mail.ru, a.v.bogomolov@gmail.ru, privalov.61@mail.ru, \\ nikolai.dobrovolsky@gmail.com
}

\begin{abstract}
The case of the active and passive team relay-race, in which an active team operates in accordance with rigid schedule and a passive team overcome the stage of its distance at randomly selected alternative routs during occasional time intervals is considered. Due to high complexity of classical relay-race analysis, method of simulation, based on representation of time intervals densities of passing stages routs with discrete distributions is proposed. It is shown, that after transformation of time intervals densities into discrete distributions the problem of a relay race analysis reduces to the task of analysis of two-team system with rigid schedules.

The method of sampling of densities composition with estimation a sampling error, and recursive procedure of rigid schedule relay-race analysis with calculation of forfeit are worked out. It is shown, that forfeit depends on the difference of stages, teams overcome at current time and a strategy, which active team realizes during relay-race.

Keywords: relay race; semi-Markov process; distance; stage; route; sampling; schedule; distributed forfeit.
\end{abstract}

\section{Introduction}

Corporative-concurrent systems, in which corporative part is represented by the team, which must overcome some distance, and concurrency is the natural environment of their existence, are widespread in manifold fields of human activity, such as economics, politics, defense, sport, etc. [1-4].

Below paired relay race is considered $[5,6]$, in which two teams, $A$ and $B$, participate. Team $A$ adheres the active strategy and has a rigid schedule of passing the distance, divided onto stages. Also team $A$ watch the team $B$, which from the point of view of team $A$ passes its stages during occasional time interval, may overcome the stage on one of possible routes, which team $\mathrm{B}$ can select randomly too. The cost of the relay race depends not only on common winning or loosing the relay-race as a whole, but on winning and loosing the stages. So the team, which passes at current time a stage with a lower number, pays the team, which is situated at the time at a stage with higher number, the forfeit, which depends on the time, until the stage inequality persists.

The analytical model of such a system, based on the semi-Markov processes theory [7-10], adopt little to computer interpretation due to extremely high computational complexity of the calculation both current functional states of the system, and the sum of forfeit, which a winner receives from a loser. To reduce complexity it is necessary to work out a special approach, oriented onto the algorithmic realization. Such approaches are currently known insufficiently, that explains the necessity and relevance of the investigations in this domain. 


\section{Model of Active and Passive Team Paired Relay Race}

Structure of paired relay race under consideration is shown on Fig. 1 [5, 6].

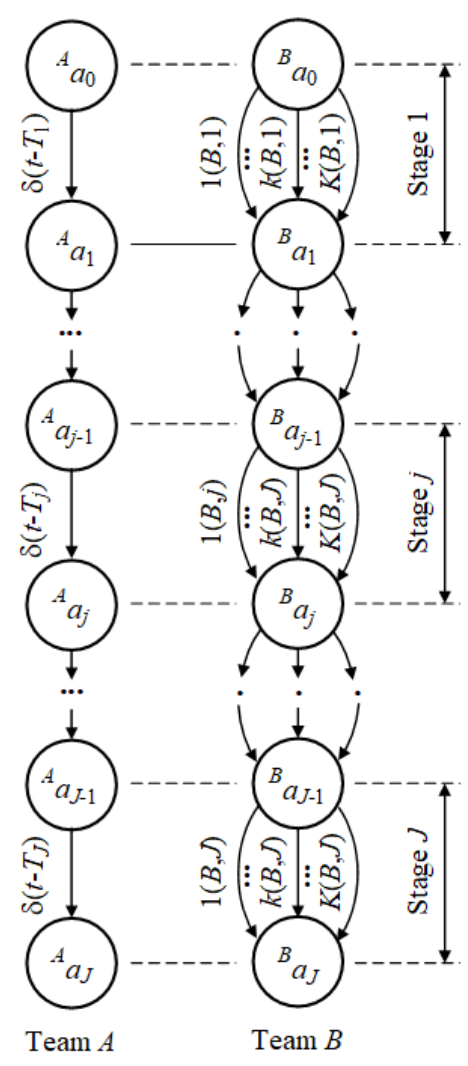

Fig. 1. Relay-races with alternative routes of the partner

On the Fig. 1:

- nodes $\left\{{ }^{A} a_{1}, \ldots,{ }^{A} a_{j}, \ldots,{ }^{A} a_{J-1}\right\}$ of graph "Team A" and $\left\{{ }^{B} a_{1}, \ldots,{ }^{B} a_{j}, \ldots,{ }^{B} a_{J-1}\right\}$ of graph "Team B" simulate relay points of the distance;

- nodes ${ }^{A} a_{0}$ and ${ }^{B} a_{0}$ simulate starting points;

- nodes ${ }^{A} a_{J}$ and ${ }^{B} a_{J}$ simulate end points of the distance.

The next assumption when modelling relay race was made:

- two teams, $A$ and $B$, participate in relay race;

- relay race unfolds in real physical time $t$;

- the distances are divided into $J$ stages;

- participants of team $A$ passes their stages in the time, predetermined with a rigid schedule;

- time intervals of passing $j(A)$-th stage, $1 \leq j(A) \leq j(B)$ by a participant from team $A$ are expressed with determinate, nonrandom values, and densities of these intervals are performed with Dirac $\delta$-functions $\delta\left(t-T_{j(A)}\right)$, where $T_{j(A)}$ is the time of passing $j$-th stage by a participant from the team $A$;

- $j$-th stage of $B$ team includes $K(B, j)$ routes;

- time intervals of passing $k(B, j), 1(B, j) \leq k(B, j) \leq K(B, j), 1 \leq j \leq J$, route by team $B$ participants are random ones and are determined with the accuracy to density $f_{k(B, j)}(t)$; 
- after finishing of $(j-1)$-th stage by the $(j-1)$-th participant from team $B j$-th participant may select one of $K(B, j)$ possible routes of $j$-th stage with probability $p_{k(B, j)}$,

$$
\sum_{k(B, j)=1}^{K(B, j)} p_{k(B, j)}=1
$$

- both teams, $A$ and $B$, start their distances at once;

- after completion of $j$-th stage by the previous participant the next participant starts $(j+1)$-th stage without a lag;

- winning or losing of a stage competition is understood as the completion of the stage the first or not the first;

- the winner's forfeit is distributed in time and depends on the difference of stages, which the winner and loser pass.

The model of the paired relay race may be performed as two-parallel semi-Markov process $[7-10]$

$$
\begin{aligned}
& { }^{A} h(t)=\left[{ }^{A} h_{j(A), l(A)}(t)\right], \\
& { }^{B} h(t)=\left[{ }^{B} h_{j(B), l(B)}(t)\right],
\end{aligned}
$$

where ${ }^{A} h(t),{ }^{B} h(t)$ are semi-Markov matrices of size $(J+1) \times(J+1)$,

$$
\begin{gathered}
{ }^{A} h_{j(A)-1, l(A)}(t)=\left\{\begin{array}{l}
\delta\left(t-T_{j(A)}\right), \text { when } 1 \leq j(A) \leq J(A) \text { and } l(A)=j(A), \\
0 \text { otherwise, }
\end{array}\right. \\
{ }^{B} h_{j(B)-1, l(B)}(t)=\left\{\begin{array}{l}
h_{j(B)}(t), \text { when } 1 \leq j(B) \leq J(B) \text { and } l(B)=j(B), \\
0 \text { otherwise, }
\end{array}\right. \\
{ }^{B} h_{j(B)}(t)=\left[h_{1(B, j)}(t), \ldots, h_{k(B, j)}(t), \ldots, h_{K(B, j)}(t)\right], 1 \leq j(B) \leq J(B),
\end{gathered}
$$

$\delta\left(t-T_{j(A)}\right)$ is the Dirac function; $T_{j(A)}$ is the rigid time of overcoming $j(A)$-th stage by $j$-th participant of the $A ; h_{k(B, j)}(t)=p_{k(B, j)} \cdot f_{k(B, j)}(t)$ is the weighted time density of overcoming $k(B, j)$-th route by $j$-th participant of team $B$.

The summation of weighted densities $h_{k(B, j)}(t)$ gives the time density of the residence of team $B$ participant at stage $j(B)$, when passing along any rout:

$$
f_{j(B)}(t)=\sum_{k(B, j)=1}^{K(B, j)=1} h_{k(B, j)}(t) .
$$

Recursive procedures of the analysis of the relay race and the evaluation of the sum of forfeit is too complicated $[5,6]$ and unsuitable for cybernation, so simplification of the procedure is quite an actual task.

\section{Discrete Model}

Let us represent time density (6) as a histogram [11, 12]. For this purpose let us divide domain $0 \leq T_{j(B) \min } \leq \arg \left[f_{j(B)}(t)\right] \leq T_{j(B) \max } \leq \infty$, where $T_{j(B) \text { min }}$ is the lower boundary of the domain, $T_{j(B) \text { min }}$ is the upper boundary of the domain, onto intervals $\tau_{\tilde{k}(B, j)-1} \leq t \leq \tau_{\tilde{k}(B, j)}, 1 \leq \tilde{k}(B, j) \leq \tilde{K}(B, j), 1 \leq j \leq J$, as it is shown in Fig. 2 . 


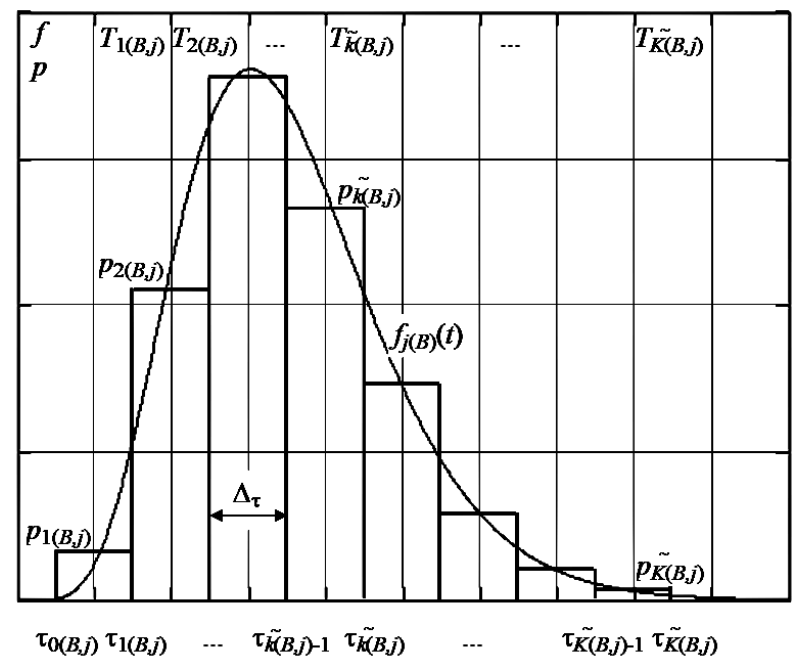

Fig. 2. The density sampling

For the definition of histogram digit parameters it is necessary to set up an accuracy $\varepsilon$ of the histogram sampling. The value of $\varepsilon$ may be calculated as follows:

$$
\varepsilon=\int_{0}^{\tau_{0(B, j)}} f_{j(B)}(t) d t+\sum_{\tilde{k}(B, j)=1_{\tau_{\tilde{k}(B, j)-1}}^{\tilde{K}(B, j)}}^{\tau_{\tilde{k}(B, j)}}\left|f_{j(B)}(t)-p_{\tilde{k}(B, j)}\right| d t+\int_{\tau_{\tilde{K}(B, j)}}^{\infty} f_{j(B)}(t) d t,
$$

where $\tau_{\tilde{k}(B, j)-1}$ and $\tau_{\tilde{k}(B, j)}$ are the left and right boundaries of $\tilde{k}(B, j)$-th, $1 \leq \tilde{k}(B, j) \leq$ $\tilde{K}(B, j)$, histogram digit, correspondingly,

$$
\begin{aligned}
\tau_{\tilde{k}(B, j)} & =\tau_{0(B, j)}+\tilde{k}(B, j) \cdot \Delta_{\tau}, \\
\Delta_{\tau} & =\frac{\tau_{\tilde{K}(B, j)}-\tau_{0(B, j)}}{\tilde{K}(B, j)} .
\end{aligned}
$$

The values of histogram digits $p_{\tilde{k}(B, j)}$ are calculated as follows:

$$
p_{\tilde{k}(B, j)}=\left\{\begin{array}{l}
\int_{0}^{\tau_{1(B, j)}} f_{j(B)}(t) d t \text {, when } \tilde{k}(B, j)=1, \\
\int_{\tau_{\tilde{k}(B, j)}}^{\tau_{\tilde{k}(B, j)-1}^{\infty}} f_{j(B)}(t) d t, \text { when } 2 \leq \tilde{k}(B, j) \leq \tilde{K}(B, j)-1, \\
\int_{\tau_{\tilde{K}(B, j)}^{\infty}}^{\infty} f_{j(B)}(t) d t \text {, when } \tilde{k}(B, j) \leq \tilde{K}(B, j) .
\end{array}\right.
$$

The density sampling task may be putted on and solved as an optimization task [13], where $\varepsilon \rightarrow \min$ is the criterion, and $\tau_{0(B, j)}, \tau_{\dddot{K}(B, j)}, \tilde{K}(B, j)$ are optimization variables.

Rigid time intervals $T_{\tilde{k}(B, j)}, 1 \leq \tilde{k}(B, j) \leq \tilde{K}(B, j)$, represented arguments of histogram digits, may be calculated as follows:

$$
T_{\dddot{k}(B, j)}=\tau_{\tilde{k}(B, j)-1}+\frac{\Delta_{\tau}}{2}, 1 \leq \tilde{k}(B, j) \leq \tilde{K}(B, j) .
$$


Taking into account (10) and (11), one may build up the semi-Markov discrete model of team $B$ operation. The structure of the semi-Markov model is quite alike the structure, shown in the Fig. 1, except that indices $k(B, j)$ of the primary model should be replaced by indices $\tilde{k}(B, j)$ in the discrete model, and in common, $K(B, j) \neq \tilde{K}(B, j)$.

Discrete operation team $B$ model, based on semi-Markov process is as follows:

$$
{ }^{B} \tilde{h}(t)=\left[B \tilde{h}_{j(B), l(B)}(t)\right],
$$

where

$$
\begin{gathered}
{ }^{B} \tilde{h}_{j(B)-1, l(B)}(t)=\left\{\begin{array}{l}
\tilde{h}_{j(B)}(t), \text { when } 1 \leq j(B) \leq J(B) \text { and } l(B)=j(B), \\
0 \text { otherwise, }
\end{array}\right. \\
{ }^{B} \tilde{h}_{j(B)}(t)=\left[p_{1(B, j)} \delta\left(t-T_{1(B, j)}\right), \ldots, p_{\tilde{k}(B, j)} \delta\left(t-T_{\tilde{k}(B, j)}\right), \ldots, p_{\tilde{K}(B, j)} \delta\left(t-T_{\tilde{K}(B, j)}\right)\right], \\
1 \leq j(B) \leq J(B),
\end{gathered}
$$

where $\delta\left(t-T_{\tilde{k}(B, j)}\right), 1 \leq \tilde{k}(B, j) \leq \tilde{K}(B, j)$ are Dirac functions; $T_{\tilde{k}(B, j)}$ are the rigid time intervals of overcoming $j(B)$-th stage by $j(B)$-th participant of team $B$.

\section{Formulae for Competition Analysis}

Due to the reduction primary model (1) - (5) to its discrete analogue (1), (3), (12) - (14), the conception of team $B$ operation may be considered as a rigid schedule [1417] relay-race with alternative routes, which on $j(B)$-th stage are occasionally selected from $\tilde{K}(B, j)$ possible routes with probabilities $p_{\tilde{k}(B, j)}, 1 \leq \tilde{k}(B, j) \leq \tilde{K}(B, j)$, after the completion $[j(B)-1]$-th stage. So general formulae, used in $[5,6]$ for working out the recursive procedure of competition and relay-races analysis should be adapted to the case under consideration, in which:

- only two teams participate in a relay-race;

- both teams operate due to rigid schedules [18, 19].

The adaptation of formulae gives the next result.

Formulae, which determine the weighted time densities of winning $j$-th stage of the race by team $A$ and team $B$, correspondingly, when both teams start their $j$-th stages simultaneously are as follows:

- in common case

$$
\psi_{A}^{w}(t)=f_{j(A)}(t)\left[1-F_{j(B)}(t)\right], \psi_{B}^{w}(t)=f_{j(B)}(t)\left[1-F_{j(A)}(t)\right],
$$

where $F_{\ldots}(t)=\int_{0}^{t} f_{\ldots}(\theta) d \theta$ is the distribution function; $\theta$ is the auxiliary argument;

- when rigid schedule

$$
\begin{aligned}
& \psi_{A}^{w}(t)=\left\{\begin{array}{l}
\delta\left(t-T_{j(A)}\right), \text { when } T_{j(A)}=\min \left\{T_{j(A)}, T_{j(B)}\right\}, \\
\text { nonsense, otherwise, }
\end{array}\right. \\
& \psi_{B}^{w}(t)=\left\{\begin{array}{l}
\delta\left(t-T_{j(B)}\right), \text { when } T_{j(B)}=\min \left\{T_{j(A)}, T_{j(B)}\right\}, \\
\text { nonsense, otherwise. }
\end{array}\right.
\end{aligned}
$$


Formulae, which determine probabilities of winning $j$-th stage of the race by team $A$ and team $B$, correspondingly, are as follows:

- in common case

$$
\pi_{A}^{w}(t)=\int_{0}^{\infty} f_{j(A)}(t)\left[1-F_{j(B)}(t)\right] d t, \pi_{B}^{w}(t)=\int_{0}^{\infty} f_{j(B)}(t)\left[1-F_{j(A)}(t)\right] d t
$$

- when rigid schedule

$$
\begin{aligned}
& \pi_{A}^{w}(t)=\left\{\begin{array}{l}
1, \text { when } T_{j(A)}=\min \left\{T_{j(A)}, T_{j(B)}\right\}, \\
0 \text { otherwise, }
\end{array}\right. \\
& \pi_{B}^{w}(t)=\left\{\begin{array}{l}
1, \text { when } T_{j(B)}=\min \left\{T_{j(A)}, T_{j(B)}\right\}, \\
0 \text { otherwise. }
\end{array}\right.
\end{aligned}
$$

Formulae, which describe the time density of waiting by the winner team until the loser team finishes the stage

- in common case

$$
\begin{aligned}
\varphi_{A \rightarrow B}(t)=\frac{\eta(t) \int_{0}^{\infty} f_{j(A)}(\theta) \cdot f_{j(B)}(t+\theta) d \theta}{\int_{0}^{\infty} F_{j(A)}(t) d F_{j(B)}(t)}, \\
\varphi_{B \rightarrow A}(t)=\frac{\eta(t) \int_{0}^{\infty} f_{j(B)}(\theta) \cdot f_{j(A)}(t+\theta) d \theta}{\int_{0}^{\infty} F_{j(B)}(t) d F_{j(A)}(t)},
\end{aligned}
$$

where $\eta(t)$ is the Heaviside function,

$$
\eta(t)=\left\{\begin{array}{l}
0, \text { when } t \leq 0 \\
1, \text { otherwise }
\end{array}\right.
$$

- when rigid schedule

$$
\begin{aligned}
& \psi_{A \rightarrow B}(t)=\left\{\begin{array}{l}
\delta\left(t-T_{j(B)}+T_{j(A)}\right), \text { when } T_{j(A)} \leq T_{j(B)}, \\
\text { nonsense, otherwise, }
\end{array}\right. \\
& \psi_{B \rightarrow A}(t)=\left\{\begin{array}{l}
\delta\left(t-T_{j(A)}+T_{j(B)}\right), \text { when } T_{j(B)} \leq T_{j(A)}, \\
\text { nonsense, otherwise. }
\end{array}\right.
\end{aligned}
$$

It is necessary to admit, that at the rigid schedules case the draw effect emerges. It is impossible in common case, when there is an infinitesimal probability of $A$ and $B$ teams stage passing time intervals coincidence, is quite real when at rigid schedule case $T_{j(A)}=T_{j(B)}$. 


\section{Recursive Procedure of Evaluation of Forfeit}

Recursive procedure of evaluation of forfeit should be considered in the twodimensional space of functional states, shown in Fig. 3 [20].

The states of space are formed as Cartesian product of sets $[1(A), \ldots, j(A), \ldots, J(A), J(A)+1]$ and $[1(B), \ldots, j(B), \ldots, J(B), J(B)+1]$. Elements of sets perform the stages, which participants of teams $A$ and $B$ overcome at the current time. There are additional elements in the sets under consideration, namely $J(A)+1$ and $J(B)+1$. These elements simulate states, which teams fall into after completion $J$-th stages of distances. The race begins from state $[1(A), 1(B)]$ and ends at state $[J(A)+1, J(B)+1]$. Wandering through the space has the character of evolution, in which after every switch one (horizontal and vertical arrows in Fig. 3) or two (diagonal arrows in Fig. 3) elements of vector $[j(A), j(B)]$ increments by unit. Switches continue until the vector reaches the state $[J(A)+1, J(B)+1]$.

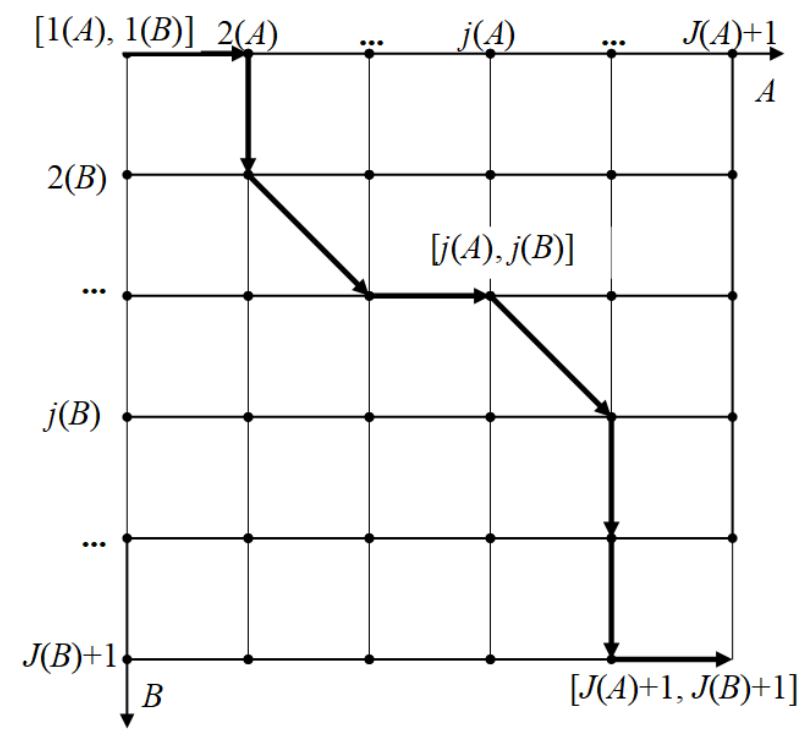

Fig. 3. The space of functional states

Time intervals of passing stage $j(B)$ depend on route $\tilde{k}(B, j)$, which team B select for passing $j(B)$-th stage. Common number of routes selected for passing distance as a whole is equal to

$$
L=\prod_{j=1}^{J} \tilde{K}(B, j) .
$$

Let us extract from all possible routes of team $B$ route

$$
s_{l(B)}=[\tilde{k}(B, 1), \ldots, \tilde{k}(B, j), \ldots, \tilde{k}(B, J)],
$$

and evaluate the forfeit, which team $A$ received from the team $B$, when evolution of team $B$ will be developed on route (23).

For evaluation of the evolution effectiveness lets utilize quite a natural model of forfeit, defined as the distributed payment by opponent team $B$ to gamer team $A, \sigma_{j(A), j(B)}(t)$, value of which depends on time. Below the case of payment by opponent team $B$ to gamer 
team $A, \sigma_{j(A), j(B)}(t)$, is considered. Rate of payment, $\sigma_{j(A), j(B)}(t)$, is as follows:

$$
\sigma_{i(A), j(B)}(t)\left\{\begin{array}{l}
>0, \text { when } i(A)>j(B), \\
=0, \text { when } i(A)>j(B), \\
<0, \text { when } i(A)<j(B),
\end{array}\right.
$$

where $1 \leq i(A), j(B) \leq J+1$.

For the evaluation of common forfeit, which team $A$ receives from $n$-th team $B$, one can use the recursive procedure, for realization of which it is necessary to introduce the auxiliary time intervals $\theta_{s}(A), \theta_{s}(B)$, where $s$ is the number of previous switches.

When starting the competition from the initial functional state $[1(A), \ldots, 1(B)]$ no switches is done $(s=0)$, substitutions $\theta_{0}(A) \Leftarrow T_{1(A)}$ and $\theta_{0}(B) \Leftarrow \tau_{1(B)}$ should be made, and time intervals $\theta_{0}(A), \theta_{0}(B)$ compete between them. A possible result of competition may be the next:

a) if $\theta_{0}(A)<\theta_{0}(B)$, then wins team $A$, and $\Theta_{0}^{*}=\left\{\theta_{0}^{*}(A)\right\}=\min \left\{\theta_{0}(A), \theta_{0}(B)\right\}$, $\theta_{0}^{*} \Leftarrow \theta_{0}^{*}(A), r=1$;

b) if $\theta_{0}(A)>\theta_{0}(B)$, then wins team $B$, and $\Theta_{0}^{*}=\left\{\theta_{0}^{*}(B)\right\}=\min \left\{\theta_{0}(A), \theta_{0}(B)\right\}$, $\theta_{0}^{*} \Leftarrow \theta_{0}^{*}(B), r=1$;

c) if $\theta_{0}(A)=\theta_{0}(B)$, then competition is in a draw, and $\Theta_{0}^{*}=\left\{\theta_{0}^{*}(A), \theta_{0}^{*}(B)\right\}=$ $\min \left\{\theta_{0}(A), \theta_{0}(B)\right\}, \theta_{0}^{*} \Leftarrow \theta_{0}^{*}(A)=\theta_{0}^{*}(B), r=2$.

The value of forfeit is equal as follows:

$$
\sigma_{s}(A, B, l)=\int_{0}^{\theta_{s}^{*}} \sigma_{1(A), 1(B)}(t) d t .
$$

Substitutions for preparing the next step of recursion are as follows:

- indices of $\theta_{0}(A), \theta_{0}(B)$, and $\sigma_{i(A), j(B)}(t)$ should be replaced with

$$
\begin{gathered}
s \Leftarrow 0+r, \\
i(A)=\left\{\begin{array}{l}
i(A)+1 \text { in the case a), } \mathrm{c}), \\
i(A) \text { in the case a), }
\end{array}\right. \\
j(B)=\left\{\begin{array}{l}
j(B)+1 \text { in the case } \mathrm{b}), \mathrm{c}), \\
j(B) \text { in the case a);}
\end{array}\right.
\end{gathered}
$$

- time intervals, which will compete further should be replaced as follows

$$
\begin{aligned}
& \theta_{s}(A) \Leftarrow\left\{\begin{array}{l}
\left.\left.T_{2(A)} \text { in the cases a }\right), \mathrm{c}\right), \\
\left.\theta_{0}(A)-\theta_{0}^{*} \text { in the case } \mathrm{b}\right),
\end{array}\right. \\
& \theta_{s}(B) \Leftarrow\left\{\begin{array}{l}
\left.\left.T_{2(B)} \text { in the cases } \mathrm{b}\right), \mathrm{c}\right), \\
\left.\theta_{0}(A)-\theta_{0}^{*} \text { in the case } \mathrm{a}\right) .
\end{array}\right.
\end{aligned}
$$

In such a way the second step or recursion rigid time intervals $\theta_{s}(A), \theta_{s}(B)$ will compete between them.

Let us assume that $(s=v)$-th step of the recursion vector of functional state of semiMarkov process is $[i(A), j(B)]$, and time intervals $\theta_{v}(A), . \theta_{v}(B)$ compete between them. The possible result of the competition may be the next: 
a) if $\theta_{v}(A)<\theta_{v}(B)$, then wins team $A$ and $\Theta_{s}^{*}=\left\{\theta_{v}^{*}(A)\right\}=\min \left\{\theta_{v}(A), \theta_{v}(B)\right\}$, $\theta_{s}^{*} \Leftarrow \theta_{v}^{*}(A), s \Leftarrow v+1$;

b) if $\theta_{v}(A)>\theta_{v}(B)$, then wins team $B$ and $\Theta_{s}^{*}=\left\{\theta_{v}^{*}(B)\right\}=\min \left\{\theta_{v}(A), \theta_{v}(B)\right\}$, $\theta_{s}^{*} \Leftarrow \theta_{v}^{*}(B), s \Leftarrow v+1$;

c) if $\theta_{s(r-1)}(m)=\theta_{s(r-1)}(n)$, then competition is in a draw, $\Theta_{s}^{*}=\left\{\theta_{v}^{*}(A), \theta_{v}^{*}(B)\right\}=$ $\min \left\{\theta_{v}(A), \theta_{v}(B)\right\}, s \Leftarrow v+2$.

The value of forfeit is calculated as follows

$$
\sigma_{s}(A, B, l)=\int_{0}^{\theta_{s}^{*}} \sigma_{i(A), j(B)}(t) d t .
$$

Substitutions for preparing the next step of recursion are as follows:

- indices of $\theta_{s}(A), \theta_{s}(B)$, should be replaced with index

$$
s \Leftarrow v+r
$$

- indices of $\sigma_{i(A), j(B)}(t)$ should be replaced in accordance with (26);

- time intervals, which will compete further

$$
\begin{gathered}
\theta_{s}(A) \Leftarrow\left\{\begin{array}{l}
\left.T_{i(A)} \text { in the cases a), c }\right), \\
\left.\theta_{v}(A)-\theta_{v}^{*} \text { in the case } \mathrm{b}\right),
\end{array}\right. \\
\theta_{s}(B) \Leftarrow\left\{\begin{array}{l}
\left.T_{j(B)} \text { in the cases b), c }\right), \\
\theta_{v}(A)-\theta_{s v}^{*} \text { in the case a). }
\end{array}\right.
\end{gathered}
$$

Let us assume, that the last step of recursion only team $A$ stays in the race, and time, it spends from a previous switch till finishing $J$-th stage, obtained on previous stage of recursion, is $\theta_{s(A)}=\theta_{s}^{*}$. The value of forfeit on the last stage in this case is equal as follows:

$$
\sigma_{s}(A, B, l)=\int_{0}^{\theta_{s()}^{*}} \sigma_{J(A)-1, J(B)}(t) d t .
$$

The common sum of forfeit, which team $A$ receives from team $B$, is as follows

$$
\sigma(A, B, l)=\sum_{s} \sigma_{s}(A, B, l)
$$

The common sum of forfeit, which $m$-th team receives from all other teams, is as follows

$$
\sigma(A, B)=\sum_{l=1}^{L} \sigma(A, B, l) .
$$

It is necessary to admit, that the common sum of forfeit, $\sigma(A, B)$, team $A$ receives from team $B$, depends of its own rigid schedule and distributions of time intervals (5). The only way to change sum of forfeit $\sigma(A, B)$ in a relay-race is changing team $A$ schedule only. This is an essential obstacle, from point of view of putting and solving the forfeit optimization task. 


\section{Conclusion}

In such a way in this paper proposed procedure of relay-races analysis, based on simulation of team $A$, as a system with a rigid schedule, and team $B$ as a system with alternative routs of passing stages. The next step of simulation is the reducing initial semiMarkov model of team $B$ activity to the abstraction with discrete distributions of passing stages time intervals, the task, as a whole, to analysis the concurrent system with rigid schedules of participants. This permits to work out rather simple computational procedure of the forfeit sum calculation.

Solving the problem of calculation the sum of the forfeit, which active team $A$ gets from its opponent team $B$, permits to work out the optimal strategy of $A$ team behaviour with use, f.e. game theory $[21,22]$. The tactics of optimal game strategies realization is to rescheduling of passing by team $A$ the remaining stages of distance at the expense of acceleration/deceleration its activity on the certain stages with taking into account restriction of its own resources, possible response of opponents etc.

Acknowledgements. The research was carried out within the state assignment of the Ministry of Education and Science of the Russian Federation (No 2.3121.2017/PCH).

\section{References}

1. Valk R. Concurrency in Communicating Object Petri Nets. Concurrent Object-Oriented Programming and Petri Nets, 2001, pp. 164-195. DOI: 10.1007/3-540-45397-0_5

2. Chatterjee K., Jurdziński M., Henzinger T. Simple Stochastic Parity Games. Lecture Notes in Computer Science, 2003, vol. 2803, pp. 100-113. DOI: 10.1007/978-3-540-45220-1_11

3. Eisentraut C., Hermanns H., Zhang L. Concurrency and Composition in a Stochastic World. CONCUR 2010-Concurrency Theory, 2010, pp. 21-39.

4. Wooldridge M. An Introduction to Multi-Agent Systems. Chichester, John Wiley and Sons, 2009 .

5. Ivutin A.N, Larkin E.V. Simulation of Concurrent Games. Bulletin of the South Ural State University. Series: Mathematical Modelling, Programming and Computer Software, 2015, vol. 8, no. 2, pp. 43-54. DOI: $10.14529 / \mathrm{mmp} 150204$

6. Larkin E.V., Ivutin A.N., Kotov V.V., Privalov A.N. Simulation of Relay-Races. Bulletin of the South Ural State University. Series: Mathematical Modelling, Programming and Computer Software, 2016, vol. 9, no. 4, pp. 117-128. DOI: 10.14529/mmp160411

7. Jiang Q., Xi H.-S., Yin B.-Q. Event-Driven Semi-Markov Switching State-Space Control Processes. IET Control Theory and Applications, 2012, vol. 6, no. 12, pp. 1861-1869. DOI: 10.1049 /iet-cta.2011.0174

8. Yang T., Zhang L., Yin X. Time-Varying Gain-Scheduling-Error Mean Square Stabilisation of Semi-Markov Jump Linear Systems. IET Control Theory and Applications, 2016, vol. 10, no. 11 , pp. 1215-1223. DOI: 10.1049/iet-cta.2015.1327

9. Korolyuk V., Swishchuk A. Semi-Markov Random Evolutions. N.Y., Springer Science and Buseness Media, 1995. DOI: 10.1007/978-94-011-1010-5

10. Limnios N., Swishchuk A. Discrete-Time Semi-Markov Random Evolutions and Their Applications. Advances in Applied Probability, 2013, vol. 45, no. 1, pp. 214-240. DOI: $10.1239 /$ aap/1363354109 
11. Bauer H. Probability Theory. Berlin, N.Y., Walter de Gruyter, 1996. DOI: $10.1515 / 9783110814668$

12. Shiryaev A.N. Probability. N.Y., Springer Science and Business Midia, 1996. DOI: $10.1007 / 978-1-4757-2539-1$

13. Squillante M.S. Stochastic Analysis and Optimization of Multiserver Systems. Run-Time Models for Self-Managing Systems and Applications. Mathematic Subject Classification. Basel, Springer Basel, 2010, pp. 1-15. DOI: 10.1007/978-3-0346-0433-8_1

14. Pinedo M.L. Scheduling. Theory: Algorithms and Systems. N.Y., Springer Science and Business Media, 2016. DOI: 10.1007/978-1-4614-2361-4

15. Khodr Y.M. Scheduling Problems and Solutions. N.Y., Nova Science, 2012.

16. Drozdowski M. Scheduling for Parallel Processing. London, Springer, 2009. DOI: 10.1007/9781-84882-310-5

17. Gawiejnowicz S. Time-Dependent Scheduling. Berlin, Springer, 2008. DOI: 10.1007/978-3540-69446-5

18. Heymann M. Concurrency and Discrete Event Control. IEEE Control Systems Magazine, 1990, vol. 10 , pp. 103-112. DOI: $10.1109 / 37.56284$

19. Larkin E.V., Ivutin A.N. "Concurrency" in M-L-Parallel Semi-Markov Process. 2017 International Conference on Mechanical, Aeronautical and Automotive Engineering (ICMAA 2017). MATEC Web of Conferences, 2017, vol. 108, no. 05003, 5 p.

20. Larkin E.V., Bogomolov A.V., Privalov A.N., Dobrovolsky N.N. Relay-Races Along Selectable Routes. Bulletin of the South Ural State University. Series: Mathematical Modelling, Programming and Computer Software, 2015, vol. 11, no. 1, pp. 16-24.

21. Attar A., Campioni E., Piaser G. On Competing Mechanisms under Exclusive Competition. Games and Economic Behavior. Toulouse School of Economics, 2015, no. TS-609, 17 p.

22. Hokan T., Thomson W. Cooperative Game Theory. International Encyclopedia of Social and Behavioral Sciences, 2015, pp. 867-880.

Received July 9, 2018

УДК 519.837

DOI: $10.14529 / \mathrm{mmp} 180306$

\section{ДИСКРЕТНАЯ МОДЕЛЬ ПАРНЫХ ЭСТАФЕТ}

\section{Е.В. Ларкин ${ }^{1}$ А.В. Богомолов ${ }^{2}$, А.Н. Привалов ${ }^{3}$ Н.Н. Добровольский ${ }^{1}$}

${ }^{1}$ Тульский государственный университет, г. Тула, Российская Федерация

${ }^{2}$ Государственный научный центр Российской Федерации - Федеральный медицинский биофизический центр им. А.И. Бурназяна, г. Москва,

Российская Федерация

${ }^{3}$ Тульский государственный педагогический университет им. Л.Н. Толстого,

г. Тула, Российская Федерация

Рассматриваются эстафеты с активной и пассивной командами, в которых активная команда работает в соответствии с жестким расписанием, а пассивная команда преодолевает стадии дистанции по случайно выбранным альтернативным маршрутам в течение случайного временного интервала. Вследствие высокой вычислительной сложности задачи классического анализа эстафет предложен метод моделирования, основанный на представлении плотностей распределения временных интервалов прохождения этапов дискретными распределениями. Показано, что после преобразования 
плотностей распределения временных интервалов в дискретные распределения задача анализа эстафет сводится к задаче анализа парных жестких расписаний.

Разработаны метод дискретизации композиции плотностей распределения с оценкой ошибки дискретизации и рекурсивная процедура анализа эстафет с жестким расписанием с расчетом суммы штрафа. Показано, что штраф зависит от разности номеров этапов, которые команды преодолевают в текущий момент, и стратегии, которую активная команда реализует в течение эстафеты.

Ключевые слова: эстафета; полумарковский процесс; дистанция; этап; марирут; дискретизация; расписание; распределенный штраф.

\section{Литература}

1. Valk, R. Concurrency in Communicating Object Petri Nets / R. Valk // Concurrent ObjectOriented Programming and Petri Nets. - 2001. - P. 164-195.

2. Chatterjee, K. Simple Stochastic Parity Games / K. Chatterjee, M. Jurdziński, T. Henzinger // Lecture Notes in Computer Science. - 2003. - V. 2803. - P. 100-113.

3. Eisentraut, C. Concurrency and Composition in a Stochastic World / C. Eisentraut, H. Hermanns, L. Zhang // CONCUR 2010-Concurrency Theory. - 2010. - P. 21-39.

4. Wooldridge, M. An Introduction to Multi-Agent Systems / M. Wooldridge. - Chichester, John Wiley and Sons, 2009.

5. Ivutin, A.N. Simulation of Concurrent Games / A.N. Ivutin, E.V. Larkin // Вестник ЮУрГУ. Серия: Математическое моделирование и программирование. - 2015. - Т. 8, № 2. - C. 43-54.

6. Larkin, E.V. Simulation of Relay-Races / E.V. Larkin, A.N. Ivutin, V.V. Kotov, A.N. Privalov // Вестник ЮУрГУ. Серия: Математическое моделирование и программирование. 2016. - Т. 9, № 4. - C. 117-128.

7. Jiang, Q. Event-Driven Semi-Markov Switching State-Space Control Processes / Q. Jiang, H.-S. Xi, B.-Q. Yin // IET Control Theory and Applications. - 2012. - V. 6, № 12. P. 1861-1869.

8. Yang, T. Time-Varying Gain-Scheduling-Error Mean Square Stabilisation of Semi-Markov Jump Linear Systems / T. Yang, L. Zhang, X. Yin // IET Control Theory and Applications. - 2016. - V. 10, № 11. - P. 1215-1223.

9. Korolyuk, V. Semi-Markov Random Evolutions / V. Korolyuk, A. Swishchuk. - N.Y.: Springer Science and Buseness Media, 1995.

10. Limnios, N. Discrete-Time Semi-Markov Random Evolutions and Their Applications N. Limnios, A. Swishchuk // Advances in Applied Probability. - 2013. - V. 45, № 1. P. $214-240$.

11. Bauer, H. Probability Theory / H. Bauer. - Berlin; N.Y.: Walter de Gruyter, 1996.

12. Shiryaev, A.N. Probability / A.N. Shiryaev. - N.Y.: Springer Science and Business Media, 1996.

13. Squillante, M.S. Stochastic Analysis and Optimization of Multiserver Systems / M.S. Squillante // Run-Time Models for Self-managing Systems and Applications. Mathematic Subject Classification. - Basel: Springer Basel, 2010. - P. 1-15.

14. Pinedo, M.L. Scheduling. Theory: Algorithms and Systems / M.L. Pinedo. - N.Y.: Springer Science and Business Media, 2016.

15. Khodr, Y.M. Scheduling Problems and Solutions / Y.M. Khodr. - N.Y.: Nova Science, 2012. 
16. Drozdowski, M. Scheduling for Parallel Processing / M. Drozdowski. - London: Springer, 2009.

17. Gawiejnowicz, S. Time-Dependent Scheduling / S. Gawiejnowicz. - Berlin: Springer, 2008.

18. Heymann, M. Concurrency and Discrete Event Control / M. Heymann // IEEE Control Systems Magazine. - 1990. - V. 10. - P. 103-112.

19. Larkin, E.V. "Concurrency" in M-L-Parallel Semi-Markov Process / E.V. Larkin, A.N. Ivutin // 2017 International Conference on Mechanical, Aeronautical and Automotive Engineering (ICMAA 2017). MATEC Web of Conferences. - 2017. - V. 108, № 05003. - 5 p.

20. Larkin, E.V. Relay-Races Along Selectable Routes / E.V. Larkin, A.V. Bogomolov, A.N. Privalov, N.N. Dobrovolsky // Вестник ЮУрГУ. Серия: Математическое моделирование и программирование. - 2018. - Т. 11, № 1. - С. 16-24.

21. Attar, A. On Competing Mechanisms under Exclusive Competition / A. Attar, E. Campioni, G. Piaser // Games and Economic Behavior. Toulouse School of Economics. - 2015. - № TS609. $-17 \mathrm{p}$.

22. Hokan, T. Cooperative Game Theory / T. Hokan, W. Thomson // International Encyclopedia of Social and Behavioral Sciences. - 2015. - P. 867-880.

Евгений Васильевич Ларкин, доктор технических наук, профессор, кафедра «Робототехника и автоматизация производства», Тульский государственный университет (г. Тула, Российская Федерация), elarkin@mail.ru.

Алексей Валерьевич Богомолов, доктор технических наук, профессор, Государственный научный центр Российской Федерации - Федеральный медицинский биофизический центр им. А.И. Бурназяна (г. Москва, Российская Федерация), a.v.bogomolov@gmail.ru.

Александр Николаевич Привалов, доктор технических наук, профессор, кафедра «Информатика и информационные технологии», Тульский государственный педагогический университет им. Л.Н. Толстого (г. Тула, Российская Федерация), privalov.61@mail.ru.

Николай Николаевич Добровольский, кандидат физико-математических наук, доцент, Тульский государственный университет (г. Тула, Российская Федерация), nikolai.dobrovolsky@gmail.com.

Поступила в редакиию 9 июля 2018 г. 